\title{
Ethics with an economic method: A new perspective on business ethics
}

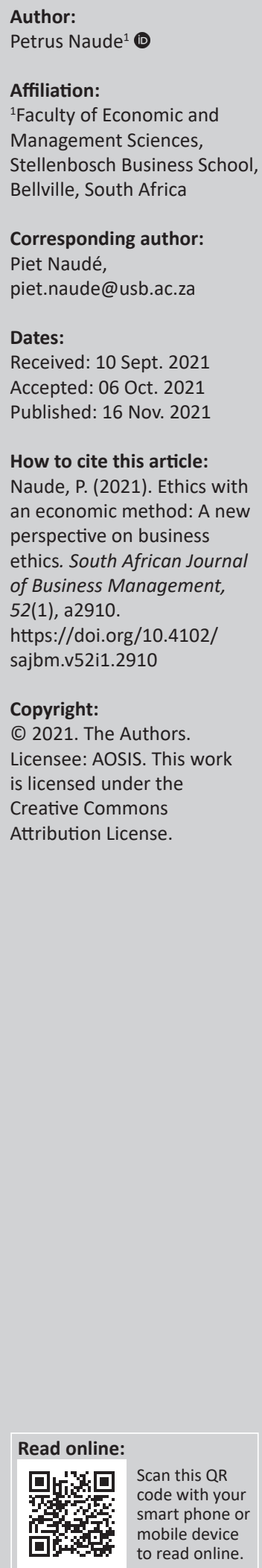

Purpose: The purpose of this article was to review the book of Christoph Lütge and Matthias Uhl (2021) entitled Business ethics. An economically informed perspective (Oxford University Press).

Design/methodology/approach: The approach followed is to give an overview of the book's content, appraise the positive contribution followed by some critical questions for further discussions.

Findings/results: The key finding is that the book, indeed, contributes to establish ethics with an economic method as a novel approach.

Practical implications: Practical implications are found in both the approach to global ethics and especially to risk management design.

Originality/value: The value of the book lies in its use as a handbook at a graduate level and as a guide to managers to implement corporate-level ethics.

Keywords: ethics; business; economics; experimental methods; global ethics; corporate ethics.

\section{Introduction}

The purpose of this short article is to review a recently published handbook for business ethics by two German authors, Christoph Lütge and Matthias Uhl (2021) entitled Business ethics. An economically informed perspective (Oxford University Press). This is a reworked English version of Wirtschaftsethik, published by Vahlen in 2018 (Lütge \& Uhl, 2018). Lütge is holder of the Peter Löscher Chair in Business Ethics at the Technical University Munich (TUM) and is one of Germany's most prolific writers on business ethical topics in both English and German, and is a co-series editor of the influential International Handbooks in Business Ethics (Springer). Uhl has recently been appointed as Professor at Ingolstadt Technical University and has co-authored quite a few publications in the field of business ethics as is evident from the references below.

The approach followed in this article is to first give a general overview of the book's content in line with the objectives set by the authors. The positive contribution of the publication to the field of business ethics is then evaluated, followed by a set of critical questions based on the findings of the content overview. The article concludes with a judgement on the practical implications and usability. of the book for students, academics and practitioners.

\section{Objectives and content overview}

The authors (2021, pp. 1-2) set a quite ambitious agenda for yet another handbook on business ethics. In summary, there are four explicit aims:

Firstly, the book summarises the state of the discipline and gives an overview of its main topics.

Secondly, it follows a comprehensive rather than specific policy approach and the former is defined by the subtitle, namely 'an economically informed' approach. This approach has two dimensions, namely, the explicit use of classical economic methods complemented by the rising importance of empirical experimental studies. The authors are convinced that this approach '... results, in many ways, in a new conception of the phenomenon of business ethics' (2021, p. 1).

Thirdly, the book follows a multidisciplinary approach and aims to appeal to students in social sciences and humanities, as well as to those from computer science, engineering and the natural sciences. 
Fourthly, although academic in nature, the book also aims to assist in the practice of business ethics, specifically in a corporate setting $(2021$, p. 2$)$.

The authors deliberately start the book (chapter 1) to situate business ethics in the context of globalisation. It allows them to demonstrate the limitations of an ethics of virtue based on individual moral action against the complexity of global institutions associated with value pluralism (2021, p. 12). This opens the door for their appeal to 'order ethics' (2021, p. 14), which focuses on institutions and the rules that govern them and explains the choice for an 'ethics of conditions', applicable to modern times, in contrast to an 'ethics of behaviour', applicable to pre-modern times (2021, pp. 42-56). The context of globalisation also prepares the reader for the three macroethical issues discussed in chapter 5, namely, poverty and inequality, human rights and dignity, and sustainability.

Chapter 2 provides the methodological key to unlock and understand the approach to business ethics 'from an economic perspective'. The authors claim to move beyond the traditional idea that we are dealing with an ethics for business, and using Nobel economist, Gary Becker's economic way of thinking, they propose business ethics as an ethic with an economic method (2021, p. 30). According to this method, human beings consistently act with a view to enhance their self-interest (however conceived). If all follow this dictum within the fair rules of a free market economy, the realisation of self-interest is, in Adam Smith's tradition, by itself an act of altruism, as it also benefits others, whether intentional or not (2021, pp. 54-55). It is therefore unreasonable to accept people to continually act against their self-interest, and neither is an ethic that does not respect that 'ought implies can' realistic or implementable.

By setting ethics up with an economic method, one can determine the empirical constraints and possibility of any course of action or policy in advance. Instead of interpreting a contradiction between 'morality' (setting an ethical standard) and economics (determine cost-benefit analyses), they are two sides of the same coin, and it results in a realistic and tenable ethics (2021, pp. 30-31; see already Lütge's doctoral dissertation 2001, pp. 83-99).

Once this methodology and new approach have been set out, the authors use chapter 3 for an eloquent defence - against popular and common sense notions - of the ethical benefits of self-interest (2021, p. 55; see Lütge, 2010), competition (2021, pp. 51-52; see Lütge, 2019, pp. 27-57) and of the market (2021, pp. 57-65), followed by an interesting discussion of different religious traditions and the prohibition of usury (2021, pp. 70-76).

As part of an overview of the subject field, chapter 4 deals with three different sets of foundations and tools for business ethics:

First is the traditional philosophical theories associated with deontology and consequentialism (2021, pp. 80-98). This is followed, secondly, by an exposition of the link between rationality and an understanding of homo economicus as 'a decision-maker who rationally maximizes her benefits' (2021, p. 106). This again underlies the notion of ethics with an economic method and experimental economic research (2021, pp. 99-108) which is '... the analysis of actual behavior of actors under incentive structures' (2021, p. 127; see Lütge, Rusch, \& Uhl, 2014). The third and very interesting additional set of foundations is related to the underestimated role of psychological factors in making moral judgments, especially social intuitionism which argues that reason has its limitation because emotional reactions to moral dilemmas precede moral reasoning (2021, pp. 135, 137).

As intimated above, chapter 5 presents an application of ethics with an economic method to global ethical issues (macro-issues) and is followed in chapter 6 by institutional or corporate ethics (meso-issues). The latter has a strong focus on compliance (important from an order ethics perspective) and the different conceptions and positive albeit the limited role of corporate social responsibility (2021, pp. 227-248).

In a very short two-page closing section (2021, pp. 305-306), the authors look towards the future of business ethics. They confirm that business ethics has now taken a respected role in business; that it must develop along interdisciplinary lines whilst becoming much more quantitative (empirical) in its approach without losing non-quantitative critical reflection. One of the main new areas for business ethics is digital ethics and ethics of artificial intelligence with a new field called CDR, or Corporate Digital Responsibility, an area to which Lütge has already made significant contributions.

\section{Positive contributions and critical questions}

This book fulfils most of the promises cited by the authors at the outset:

It does give an update on the current state of business ethics as a discipline with a very useful glossary for quick reference to key terms (2021, pp. 307-318), which is of great value to managers and practitioners. An added benefit of the book is the introduction to English-speaking readers of specific German case studies, German public policies, and references to leading German authors like Karl Homann whose work is not readily available to a wider reading public. The book follows a multidisciplinary approach mostly drawing on philosophy, psychology, and - key to the book - classical economics and empirical experimental science.

The case for 'ethics with an economic method' is clearly set out and does make a new contribution to our understanding of business ethics. In this sense, the book is more than just a general handbook, but an intellectual contribution to management theory as such. For leaders and managers in multinational corporations, the discussion of global ethical issues (inequality, human rights and sustainability) provides useful guidelines to address some of the most pertinent questions faced by those operating businesses across different jurisdictions. The chapter on corporate ethics is the most 
'applied' section of the book and provides managers with a set of clear guidelines of how to design and implement compliance and risk management (see chapter 6.1 and Lütge \& Jauernig, 2014, specifically pp. 3-16 and pp. 45-70).

In the spirit of collegial academic discussion, the following constructive-critical remarks are made:

In the foundations for business ethics (chapter 4), virtue ethics is not accorded the same status as other philosophical approaches, such as deontology and consequentialism. There is, therefore, no proper discussion of Aristotle or MacIntyre or feminist ethics. The reason is the authors' overtly sceptical view of virtue as an outdated (pre-modern) and even superfluous (2021, p. 239) ethical stance, as is clear from their discussion of the 'honorable businessman' (2021, pp. 236-238, see Lütge \& Strosetzki, 2019). Personal virtue, they think, might only have value for small- or medium-sized businesses. They therefore miss both the translation of virtue to modern or post-modern institutional culture and the role that virtuous corporate leaders still play in making decisions with global impact.

By holding on to a strict interpretation of 'ought implies can', the authors underestimate the crucial aspirational role that ethics plays. They implicitly recognise this in the discussion of company codes where not all ethical ideals and values are in fact realised as the code invites moral behaviour whilst accepting the necessary gap between 'ought' and 'can'. This has specific relevance to, for example, second order constitutional rights to education, healthcare and housing. It is in most countries impossible for the state and private sector to realise these rights, but that neither mean their progressive realisation ('can') is given up, nor are the ideals set in the constitution ('ought') abandoned because of a lack of implementation of resources.

A book review is not the place to engage in paradigmatic discussions. The following statements about 'ethics with an economic method' are therefore made without full justification and only serve as pointers for further discussion:

By bringing all human desires under the rubric of self-interest (following Gary Becker's idea of an economic way of thinking about all human action), concepts like 'altruism' and 'philanthropy' are rendered vacuous as they are themselves presented in the logic of rational self-interest. In this way even the self-less actions of a Mother Theresa are seen as emanating from homo economicus. (For a critique of this as a form of invasive logic, see Naudé, 2020).

By taking rational choice for self-interest as methodological starting point, the authors overlook their own admission that rationality in moral decisions and human behaviour is overestimated because of social conditions at the time of decisions and the psychology related to intuitions.

By assuming, despite empirical contradictions, the trickledown effect of market actions, the authors underestimate and at times ignore the reality that 'not all boats rise when the tide comes in'. The scant two references to Nobel prizewinning economists like Sen and no mention of Stiglitz's views are omissions from the book, which could have resulted in a more balanced perspective than the orthodox views held by the authors.

By asserting quite strongly that ethics with an economic method implies and in fact requires the enhancement of selfinterest, it becomes very difficult to provide moral guidance in cases where self-interest is required to be suspended like alluded to in the discussion of 'self-binding' (2021, p. 188). For example, an oil company that wishes to make the transition to non-fossil energy, might be required to restrict its current rate of monetary returns (institutional selfbinding?) for quite a lengthy period beyond the current management's term who is in fact required to act against their self-interest (reduced bonus payments) in the hope that beyond their own time the company will benefit.

Although the authors emphasise that they do not make any ontological assumptions about human beings but simply describe how humans in fact behave, they do at times slip into generalisations of an ontological kind. In their discussion that it is irrational and empirically doubtful to ask people to reduce consumption to save natural resources, they motivate as follows: '[e]xpansion is a fundamental aspect of human nature' (2021, p. 191). This statement flows from the underlying commitment to the economic way of thinking and makes a strong essentialist claim about human nature that is probably assumed in Western, developed economies.

These questions do not detract from the overall quality and value of this book, and are in fact a testimony to the challenge to rethink business ethics as put forward by the authors.

\section{Conclusion}

This handbook makes an original contribution to business ethics and advances the status of the discipline. As a result of its relatively complex expositions, the book would be suitable for students in their third or final year of under-graduate studies and for any post-graduate orientation at Honours and Masters level. Businesspeople and practitioners will gain valuable insights from the many useful case studies, reflections on global issues, and specifically the section on corporate ethics.

Oxford University Press and the authors are to be thanked for their efforts to produce a book of high quality.

\section{Acknowledgements Competing interests}

The author declares that he has no financial or personal relationships that may have inappropriately influenced him in writing this article.

\section{Author's contributions}

P.N. is the sole author of this research article. 


\section{Ethical considerations}

This study followed all ethical standards for research without direct contact with human or animal subjects.

\section{Funding information}

This research work received no specific grant from any funding agency in the public, commercial or not-forprofit sectors.

\section{Data availability}

Data sharing is not applicable to this article as no new data were created or analysed in this study.

\section{Disclaimer}

The views and opinions expressed in this article are those of the author and do not necessarily reflect the official policy or position of any affiliated agency of the author.

\section{References}

Lütge, C. (2001). Ökonomische Wissenschaftstheorie. Würzburg: Königshausen \& Neumann.

Lütge, C. (2010). Economics and ethics: How to combine ethics and self-interest. In J. Rendtdorff (Ed.), Power and principle in the market place. On ethics and economics (pp. 63-72). London: MPG Books.

Lütge, C. (2019). The ethics of competition. How a competitive society is good for all. Cheltenham: Edward Elgar.

Lütge, C., \& Jauernig, J. (Eds.). (2014). Business ethics and risk management. Heidelberg: Springer.

Lütge, C., Rusch, H., \& Uhl, M. (Eds.). (2014). Experimental ethics. Toward an empirical moral philosophy. London: Palgrave Macmillan.

Lütge, C., \& Strosetzki, C. (Eds.). (2019). The honorable merchant - Between modesty and risk-taking. Heidelberg: Springer.

Lütge, C., \& Uhl, M. (2018). Wirtschaftsethik. München: Franz Vahlen.

Lütge, C., \& Uhl, M. (2021). Business ethics. An economically informed perspective. Oxford: Oxford University Press.

Naudé, P. (2020). Market society? A critical reflection on its nature and socio-ethical implications. In M. Höfner \& B. Friedrich (Eds.), Gottes Gegenwart - God's presences. Festschrift für Günther Thomas zum 60. Geburtstag (pp. 257-267). Berlin: Evangelische Verlagsanstalt. 